\title{
La vivienda en la construcción de la independencia energética y alimentaria familiar
}

The Family dwelling in the construction of food and energy independence

\section{Autores}

Dr. Felipe Albino Gervacio

Mtro. Jorge Alejandro Alcérreca Huerta

\section{Resumen}

La vivienda es clave en la construcción del desarrollo sustentable y a ella suelen dirigirse las inversiones patrimoniales encargadas de fortalecer a la familia. Contemplar esta visión es fundamental para el mejoramiento de la calidad de vida dentro de un Estado que atiende más al mejoramiento de los flujos del capital que al desarrollo humano de sus pobladores. La producción y aprovechamiento tanto energético como de alimentos pueden contribuir en la independencia económica familiar otorgándoles una mayor seguridad.

\section{Palabras clave}

Vivienda; Independencia económica familiar; Independencia energética y alimentaria familiar

\begin{abstract}
Dwelling is an important key to build the sustainable development and the locus where familial investments take place to strengthen the family. It is necessary to regard this vision to ameliorate the life's quality in a State which its objectives are the improvement of money flows more than those of the human development of its inhabitants. Energetic and feeding production in addition to its profit can contribute in the home economics independence, granting more security to the families.
\end{abstract}

\section{Keywords}

Dwelling, Home economics independence, Familial energetic and feeding independence

\section{Sumario}

0. Introducción

1. La eficiencia energética en la vivienda

2. Entropía

3. Arquitectura y entropía

4. Arquitectura vernácula

5. El nuevo camino de la arquitectura

6. Tendencias actuales de la "arquitectura ecológica"

7. Una vivienda económicamente productiva

8. Retos del modelo de vivienda

9. Socialización de la ciencia y la tecnología

10 Conclusiones 
"¿Está capacitada la ciencia ante la tarea que enfrentamos -equipar a las sociedades humanas para manejar el medio ambiente de manera sustentable?"

Redclift $^{1}$

\section{Introducción}

Actualmente la arquitectura no debe dedicarse exclusivamente a desarrollar "vivienda verde" 0 atender a "consejos prácticos" que permitan optimizar los recursos energéticos en la misma, ya que aunque útiles, éstos no resuelven la problemática de fondo.

En México, el consumo energético de la vivienda es relativamente bajo respecto a otros países si es que medimos este consumo en base a las emisiones de carbón hacia la atmósfera, aunque no se mida en la totalidad sus impactos ambientales, ya que las emisiones de $\mathrm{CO} 2$ promedio de un país pueden llegar a incrementarse si la electricidad se produce en su mayoría en plantas termoeléctricas que de plantas hidroeléctricas. ${ }^{2}$ He aquí un ejemplo de problema en un sistema complejo $^{3}$ construido por distintos subsistemas que actúan entrópicamente ${ }^{4}$ entre sí.

La problemática de la vivienda en México no se encuentra exclusivamente en el exceso de emisiones de $\mathrm{CO} 2$ a la atmósfera que ésta genera por concepto de consumo de energía ya que es muy bajo, por lo que la pregunta es: ¿Para qué quiere nuestro país una vivienda energéticamente más eficiente? Ahora bien, podría tratarse de resol-ver el excesivo consumo de electricidad, de gas o satisfacer las demandas de agua, pero dedicarnos a ahorrar por el ahorro mismo limita nuestra visión como arquitectos.

Los problemas energéticos del país en torno a la vivienda podríamos englobarlos en tres rubros principales: desde la producción de la energía requerida, hasta la construcción o renovación de la misma y el consumo, entre otros aspectos.

Dado lo anterior, es necesario aclarar que esta investigación está enfocada al consumo de energía y materia en la vivienda de tal manera que las familias consumidoras de energía puedan ser verdaderamente dueñas de su energía al reducir su consumo y producir una parte de la misma. Se trata de otorgar a los dueños de una vivienda herramientas para obtener una progresiva independencia energética de la red municipal o delegacional otorgando también a la familia el papel de lograr con su

$1 \quad$ Michael R. Redclift es profesor de Política Internacional Ambiental y jefe del grupo de investigación de Ambiente, Sociedad y Política en el Departamento de Geografía del King's College en Londres. Recientemente ha sido el autor de Chewing Gum: The Fortunes of Taste and Sustainbility: Critical Concepts in Social Theory.

2 N. del A. Las citadas plantas hidroeléctricas pueden tener un impacto negativo en el anegamiento de cuencas que las deterioran al destruir sus ecosistemas sin necesidad de emitir grandes cantidades de $\mathrm{CO}_{2}$ a la atmósfera, ante esta problemática, la cátedra UNESCO de sostenibilidad llevada a cabo por la UPC (Universidad Politécnica de Cataluña) aborda el agua y saneamiento de forma transversal con una visión integral del ciclo hidrológico, haciendo frente a los desafíos que impone el cambio climático.

3 Según Rafael López Rangel: "[En el] paradigma del sistema complejo todos los sistemas complejos están determinados por múltiples complejos que están interdefinidos el uno con el otro, y la parte con el todo".

4 N. del A. Según la RAE la entropía es la "magnitud termodinámica que mide la parte no utilizable de la energía contenida en un sistema". A lo largo de este estudio hago una mención más clara del concepto. 
vivienda una mayor independencia económica dentro de la producción agrícola urbana, aislándose de los caprichos que el mercado impone a los precios de los alimentos.

Pero cuando encontramos soluciones tan variadas para construir una vivienda energéticamente eficiente y económicamente productiva nos encontramos que es sólo una de tantas soluciones que se inscriben dentro de un problema sumamente complejo derivado de entender que la civilización genera entropía, por lo que la vivienda es un pequeño agente generador de esa entropía.

Es difícil creer que se pueda resolver la entropía en una vivienda y menos en la civilización, aunque se puede reducir y controlar dentro de un esquema más amplio que sea la economía nacional: algo así como una suma de participaciones individuales ciudadanas a nivel familiar que repercutan positivamente en la reducción entrópica de la energía en la sociedad. Este control basado en la optimización energética de la vivienda sólo se puede entender ligándolo al estudio de un problema cuya complejidad es mayor: la entropía de la civilización.

La reducción entrópica en el hogar podría generar una independencia en la economía familiar. Al reforzar la reducción entrópica con estrategias dirigidas a la producción energética y reducción de su gasto con una producción agrícola urbana, se puede contribuir a una gestión independiente para inscribir estas estrategias en el marco del desarrollo sustentable de la vivienda entendida bajo los preceptos de un hogar, contemplando a la familia como lo más importante de la misma.

Entender la vivienda dentro del marco del desarrollo sustentable podría ser una de las claves para lograr un considerable aumento del bienestar del país habiendo contemplado mucho antes la calidad de vida de los hogares construidos por millones de familias, ya que "una vivienda energéticamente más eficiente y económicamente productiva" podría reducir la presión que los habitantes del país ejercen sobre sus empresas paraestatales generadoras de energía. Es muy importante recordar que las directrices de los gobiernos neoliberales intentan recortar los subsidios sobre el suministro de energía y recursos como el agua, desprotegiendo a la población que lo sostiene y elige para su representación.

Con una menor presión, las empresas paraestatales podrían apostar por otros medios de obtención energética más eficientes. ${ }^{5} \mathrm{O}$ en el peor de los casos, las familias cuyas características sean similares a las presentadas en este estudio pueden encontrar protección contra las arbitrariedades de su propio gobierno. ${ }^{6}$

El presente estudio no pretende descubrir novedosas estrategias de optimización energética para la vivienda de nuestro país, sino que pretende enfocar esas estrategias de optimización energética dentro de la vivienda para obtener una respuesta a las presiones existentes y alcanzar así "una vivienda energéticamente más eficiente" encontrando una creciente independencia del mercado de alimentos con "una vivienda económicamente productiva".

\footnotetext{
5 Según James Lovelock "...insisto en que necesitamos la energía nuclear porque no exis te ninguna otra alternativa segura y fiable para la producción de electricidad a gran escala" en LOVELOCK, James. La venganza de la Tierra: La teoría de Gaia y el futuro de la humanidad. México, Ed. Planeta, 2007.

6 N. del A. Cuenta Facundo Cabral: "Un presidente argentino, cuando le presenté a mi madre le dijo: 'Qué gusto de conocerla Sara, ¿en qué puedo ayudarla?' Y mi madre le dijo: 'Conque no me joda es suficiente."'
} 
Las presiones para obtener "una vivienda energéticamente más eficiente" son claras ante el constante aumento de la energía para calentar agua (gas), advertencias como las del gobierno de la Ciudad de México de racionar el suministro de agua y cortarlo, así como la ineficiente producción eléctrica cuyos manejos pueden desencadenar un alza en el precio de consumo, sin añadir la constante presión de los gobiernos neoliberales por retirar los subsidios.

¿A quién le conviene la producción de una vivienda energéticamente más eficiente en nuestro país? Hay que tomar en cuenta que la familia no suele contemplarse en la construcción de la vivienda puesto que aquélla pasa a un segundo término después de los flujos del capital. Es por eso que es a la familia a la que hay que fortalecer y proteger, ya que si el Estado se preocupara de fortalecer a las familias que son susceptibles de pagar impuestos, el mismo Estado se beneficiaría, reduciendo la economía informal y ampliando la base fiscal.

Este estudio deberá otorgar nuevas perspectivas en la definición de lo que es "una vivienda energéticamente más eficiente" pero bajo la búsqueda de soluciones que pongan por encima de cualquier cosa (incluso por encima de los flujos del capital) al ser humano y lo que es realmente importante para el mismo, que son los lazos afectivos cuyos orígenes se encuentran en la familia.

Las soluciones que se obtengan deberán permitir que las familias encuentren en su vivienda una manera de protegerse ante las presiones neoliberales que buscan escatimar cada vez más su calidad de vida. La inversión de recursos que se dirijan a mejorar la calidad de vida de la familia repercutirán positivamente en el desarrollo del país, pero actualmente el desarrollo armónico de la familia se encuentra amenazado por las políticas adoptadas por un gobierno que debería velar por la integridad de la misma familia y no lo hace, impulsado por el actual modo de producción. Debemos recordar constantemente que la vivienda es el hogar antes que un medio de lucro.

El caso de la producción de alimentos a escala urbana puede generar una independencia alimentaria para contribuir positivamente en la seguridad y soberanía nacionales. Probablemente se pueda generar una estabilidad económica al sector socioeconómico medio en la que dentro de un marco de formalidad pueda contribuir con sus impuestos a la estabilidad del Estado, fortaleciéndolo.

Existe una interrogante que sólo la puesta en práctica de proyectos que contemplen el desarrollo sustentable y la socialización de la ciencia deben responder: Mientras una persona o una sociedad cuente con más recursos para cubrir sus necesidades, ¿ésta o aquélla relegará cada vez más la necesidad de desarrollarse sustentablemente? El dicho reza: "Mientras más ganas, más gastas". Aquella pregunta, extrapolándola a la humanidad sólo será respondida si evitamos la destrucción de la raza humana.

Hay que apelar a la propagación y desarrollo de un espíritu que respete profundamente la vida, porque la vivienda es el espacio más importante en el que se construye la familia, siendo estratégica en la conformación de la calidad de vida de todos nosotros.

El presente artículo se estructura de la siguiente manera: 
a) La eficiencia energética en la vivienda, en donde se analizan los conceptos de entropía en su relación con los orígenes de la arquitectura, así como sus nuevas tendencias.

b) Una vivienda económicamente productiva, en la que la agricultura urbana puede ser una oportunidad para lograr la independencia alimentaria familiar

c) Retos del modelo de vivienda ante los que se enfrenta el diseño de una vivienda que contribuya a la independencia energética y alimentaria familiar.

d) Socialización de la ciencia y la tecnología para la que se rescatan conceptos necesarios para el entendimiento de la vivienda en la construcción del hogar y la familia.

e) Conclusiones

\section{La eficiencia energética en la vivienda}

"Antes de iniciar la labor de cambiar al mundo, da tres vueltas por tu propia casa"

Proverbio chino

El objetivo de este estudio es contemplar a la vivienda dentro de un marco de autoproducción que reduzca sus impactos entrópicos por medio de dos estrat egias:

- $\quad$ Eficiencia energética

- $\quad$ Autoproducción agrícola urbana

Esto es para convertir a la vivienda en un instrumento de conservación patrimonial familiar en un intento por conquistar una independencia energética y alimentaria de la familia encaminada a la generación de políticas dirigidas al desarrollo sustentable.

Al tomar como punto de partida una pregunta que había yo realizado en la introducción de este estudio que es: "¿Para qué quiere nuestro país una vivienda energéticamente más eficiente?" podemos ver que la arquitectura es una de las actividades más entrópicas que existen, ya que:

En el mundo, las edificaciones absorben el $50 \%$ de todos los recursos mundiales en su construcción y un $45 \%$ de la energía para mantenerlas. También el $60 \%$ de la mejor tierra cultivable que deja de utilizarse para la agricultura se utiliza para la construcción. ${ }^{7}$

Como un ejercicio, sería bueno analizar un indicador de eficiencia energética para tratar de responder a la pregunta anteriormente mencionada y es, por poner un ejemplo, las emisiones totales anuales de CO2 a la atmósfera debidas a la energía utilizada en los hogares (v. tabla 1).

\footnotetext{
7 EDWARDS, Brian. Guía básica de la sostenibilidad. España, Ed. Gustavo Gili, SA, 2005. Es evidente que los porcentajes varían de una región a otra, podemos ver en la República Mexicana que el costo promedio para enfriar una vivienda en la Ciudad de México es casi nulo en comparación con viviendas localizadas al norte en ciudades como Tijuana, Mexicali, etc. Los costos de calentamiento de una vivienda en los países desarrollados de Europa y Estados Unidos son en promedio mucho mayores que los que se pudieran obtener en los países en vías de desarrollo. N.del A.
} 
En el año de 2006 las emisiones de CO2 debidas al consumo energético en la vivienda de nuestro país estuvieron por debajo de los $500 \mathrm{~kg}$ per cápita ${ }^{8}$ y es notable que en nuestro país las emisiones citadas se encuentran por debajo de las de países como Cuba y Argentina (con emisiones ligeramente mayores) o Polonia y Serbia (con emisiones del orden de 2,500 kg per cápita), mientras que Kuwait, Bahrein y los Emiratos Árabes Unidos presentan emisiones que superan los 5,000 kg per cápita.

Siguiendo con este ejercicio, el consumo de energía eléctrica en México ${ }^{9}$ es de 1,968 $\mathrm{kWh} / \mathrm{hab}$ contra $1,152 \mathrm{kWh} / \mathrm{hab}$ de Cuba en el mismo año y 2,418 kWh/hab en Argentina. En el caso de Polonia, encontramos 3,437 kWh/hab y $11,401 \mathrm{kWh} / \mathrm{hab}$ para el caso de Bahrein.

La producción de electricidad en México proviene en $78.86 \%$ de la quema de hidrocarburos y carbón ${ }^{10}$ mientras que la producción de electricidad en Cuba, por comparación, procede en $99.6 \%$ de la quema de hidrocarburos, carbón, leña y productos de caña ${ }^{11}$ lo cual puede explicar por qué Cuba produce mayores emisiones de CO2 per cápita por vivienda a la atmósfera que México y viendo la Tabla 1 realizada por National Geographic (aunque hay que añadir aspectos como la calidad de las plantas termoeléctricas), caso que puede repetirse en países como Emiratos Árabes Unidos, Kuwait y Bahrein cuya producción de petróleo les puede permitir generar electricidad a partir de plantas termoeléctricas de una forma tan barata que no necesitan preocuparse por buscar fuentes de producción alternas. Hay que notar que en el caso de los Emiratos Árabes Unidos, las plantas termoeléctricas presentan casi el $100 \%$ del parque productor de electricidad. ${ }^{12}$

Existen países que tienen otro tipo de producción de energía eléctrica como en Islandia. Las emisiones de $\mathrm{CO} 2$ de Islandia son "casi nulas" debido a que su energía proviene casi en su totalidad de plantas hidroeléctricas $(74.4 \%)$, jugando un papel importante las plantas geotérmicas $(20.5 \%)$, mientras que el $5.1 \%$ de la electricidad se obtiene en plantas termoeléctricas. ${ }^{13}$

\footnotetext{
8 National Geographic. "Energy for tomorrow (repowering the planet). Collector's edition". 2009. p 43. Una imagen global de lo que estoy tratando de decir se puede observar en la tabla que muestra las emisiones totales de $\mathrm{CO}_{2}$ debido a la energía utilizada en los hogares medida en kilogramos per cápita. "Las emisiones de dióxido de carbono que contribuyen al calentamiento global debidas al uso de la electricidad y quema de combustibles varían mucho de un país a otro dependiendo del clima local y de las condiciones económicas. [La tabla 1] no incluye otros combustibles como la leña, utilizada extensamente en países en vías de desarrollo, lo cual alteraría la gráfica".

9 Datos extraídos del Banco Mundial. Vid. http://web.worldbank.org/WBSITE/EXTERNAL/DATASTATISTICS/ 0, ,contentMDK:20535285 menuPK: 1192694 pagePK:64133150 piPK:64133175 theSitePK:239419,00.ht $\mathrm{ml}$ (ingresada el 20 de septiembre de 2009). Se trata de datos del año de 2005.
}

10 Datos extraídos de Castro Soto, Gustavo. Radiografía de la Electricidad en México. Vid. www.ecoportal.net/content/view/full/67368 (ingresada el 20 de septiembre de 2009).

11 Datos extraídos de "Estadísticas de Energía de Cuba a partir del Anuario de Cuba del 2007". Vid. Portal cubano de la energía: www.energia.inf.cu (ingresada el 20 de septiembre de 2009).

12 Vid. Portal de energía de los Emiratos Árabes Unidos: www.eia.doe.gov/emeu/cabs/UAE/Full.html (ingresada el 20 de septiembre de 2009).

13 Datos extraídos del Ministerio de Industria, Energía y Turismo de Islandia. Vid. www.statice.is (ingresada el 20 de septiembre de 2009). 
El caso del consumo de la energía en la vivienda parece hacerse más complejo, ya que a la anterior pregunta: "¿Para qué quiere nuestro país una vivienda energéticamente más eficiente?" Sólo hemos podido atisbar algunos aspectos haciendo referencia a la producción de electricidad.

Es urgente crear un sistema de producción, distribución y gasto de energía en la conformación de políticas públicas que conciernen a una mejor organización de la eficiencia energética de las naciones por parte de sus aparatos estatales. Pero al respecto parece que vamos hacia atrás, puesto que en lugar de analizar el problema como un sistema complejo, sólo tratamos de contestar la siguiente pregunta: "¿Cómo le hacemos para obtener más energía barata y así continuar nuestro sistema de vida?" Haciendo referencia clara a la necesidad de continuar con un capitalismo sustentable, que como aseguraba James O'Connor, es imposible.

Las acciones de la familia en la instauración de una eficiencia energética sólo pueden circunscribirse a la vivienda. La reducción en las emisiones de CO2 por el transporte debe provenir de una adecuada planeación urbana y políticas públicas que actúen dentro de los marcos de la macroeconomía de un país. Es necesario crear mecanismos que permitan medir adecuadamente la huella ecológica de los habitantes de nuestro país para tener indicadores que nos ayuden a actuar con eficacia.

Resumiendo las acciones que una sociedad puede realizar para lograr una mayor eficiencia energética podríamos resumirlos de manera sencilla en los siguientes niveles de acción:

- A gran escala o correspondientes al desarrollo y seguimiento de políticas públicas.

- Transporte

- Industria

- Todos los referentes al campo de acción del gobierno

- A pequeña escala o correspondientes al desarrollo de una ética comprometida. ${ }^{14}$

- Vivienda

- Hábitos de consumo

14 Es necesario mencionar que los niveles de acción a pequeña y gran escala necesitan una dirección más profunda ligada con la cosmogonía del ser humano. N. del A. 


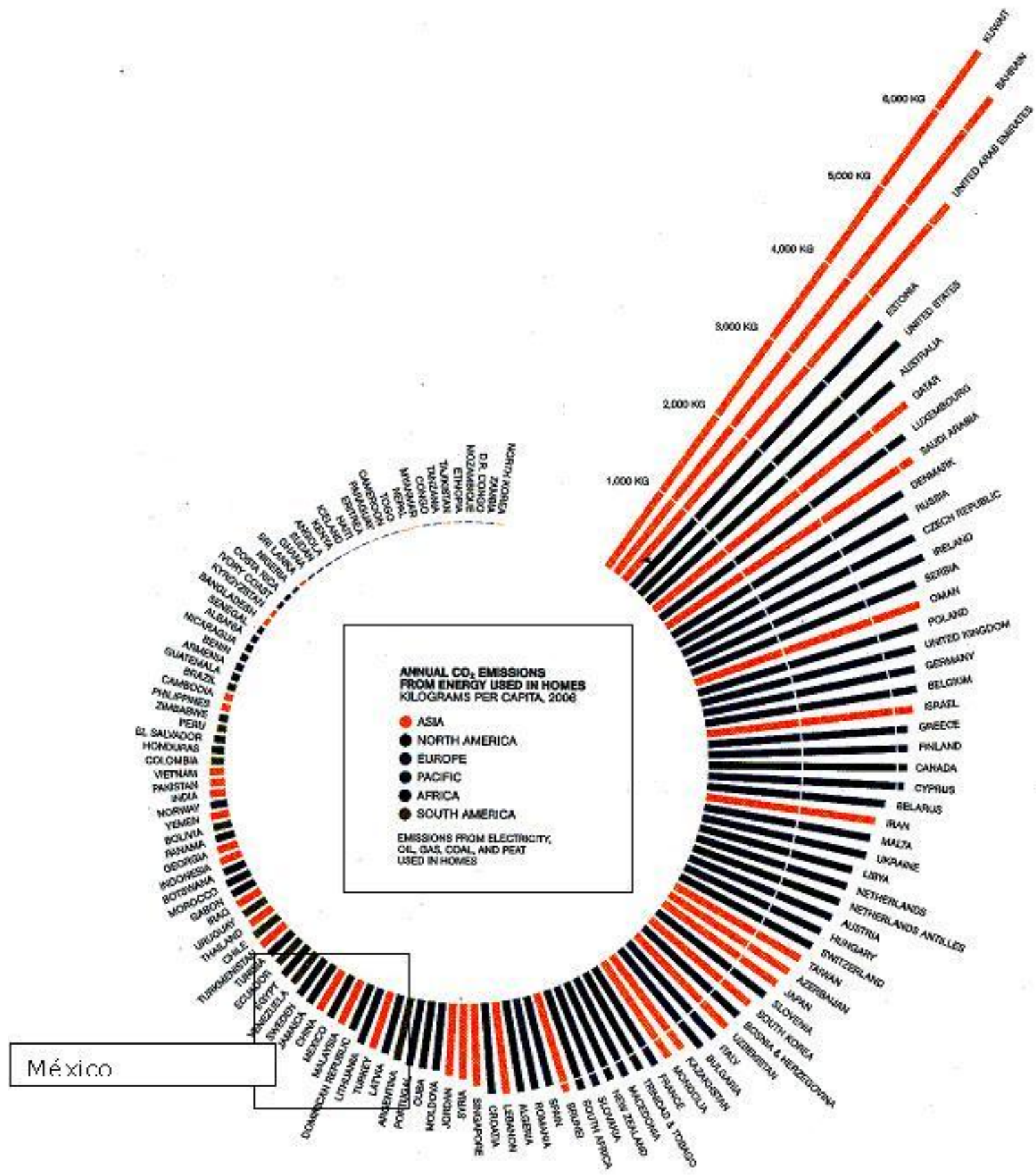

Tabla 01

Emisiones totales anuales de $\mathrm{CO} 2$ debido a energía utilizada en hogares. Kilogra-mos per cápita, 2006.

Las emisiones de dióxido de carbono que contribuyen al calentamiento global debidas al uso de la electricidad y quema de combustibles varían mucho de un país a otro dependiendo del clima local y de las condiciones económicas. [La tabla 1] no incluye 
otros combustibles como la leña, utilizada extensamente en países en vías de desarrollo, lo cual alteraría la gráfica. ${ }^{15}$

En este estudio, analizo la mayor eficiencia energética en la vivienda, a pequeña escala, aunque los hábitos de consumo pueden ser ponderados en algunos aspectos. Es evidente que se puede intentar cambiar los hábitos de consumo como parte de un compromiso personal, pero no es suficiente con querer cambiar nuestra forma de vida, porque el cambio de los hábitos de consumo del ser humano debe partir del reconocimiento de una actitud instaurada en el subconsciente del mismo que lo ha convertido en herramienta de los flujos del capital, el ser humano termina siendo víctima de sus propias invenciones. ${ }^{16}$

Existen experimentos como el realizado por National Geographic que sólo responden a los intereses del capitalismo sustentable. ${ }^{17}$

Decidimos hacer un experimento. Durante un mes medimos nuestras emisiones personales de dióxido de carbono ( $\mathrm{CO} 2)$ como si contáramos calorías. Queríamos ver cuánto podíamos ahorrar, así que nos pusimos una dieta estricta. ${ }^{18}$

Es de notar que las emisiones de carbono en vivienda en los Estados Unidos según la Tabla 1 son ocho veces mayores que en México.

Es creciente la problemática que existe en la producción de energéticos. A esto se añade un deficiente diseño en el aprovechamiento energético de los hogares, que de atenderse contribuiría a disminuir el impacto sobre el planeta, "para vivir como vivimos, somos demasiados"19 y esta aseveración nos da a entender que muy probablemente el problema al que nos enfrentamos tiene también un orden cualitativo más allá del orden cuantitativo. Es necesario reconocer y dar cabida a otros estilos de vida que tienen un impacto energético menor en el planeta, o por decirlo así, un impacto entrópico menor.

$15 \quad$ National Geographic. Op cit. p 43.

16 "La necesidad de dinero -escribió [Marx] en los Manuscritos económico-filosóficos-es, pues, la necesidad real creada por la economía moderna y la única necesidad que ésta crea... Esto se demuestra subjetivamente, en parte por el hecho de que la expansión de la producción y de las necesidades se convierte en una servidumbre ingeniosa y siempre calculadora a los apetitos inhumanos, depravados, antinaturales e imaginarios." FROMM, Erich. Marx y su concepto del Hombre. México, Ed. FCE, 2005. p 37.

17 James O'Connor explica que aunque es muy difícil la puesta en marcha de un capitalismo sustentable, tal vez pueda haber esperanzas en un socialismo ecológico, "pero los movimientos sociales individuales son relativamente impotentes frente a la fuerza totalizadora del capital global". O'CONNOR, James. ¿Es el capitalismo sostenible? En ALIMONDA, Héctor (comp.) Ecología política, naturaleza, sociedad y utopía. Buenos Aires, CLACSO, abril de 2002. Vid. http://bibliotecavirtual.clacso.org.ar/ar/libros/ecologia/ ecologia.html (ingresada el 19 de febrero de 2010). p 48.

18 MILLER, Peter. "Ahorro de energía, se empieza en casa" en: National Geographic en español. Vol 24 no. 03. Fecha de publicación: 26 de febrero de 2009. pp. 2-23, p 5.

19 LOVELOCK, James. La venganza de la Tierra (la teoría de Gaia y el futuro de la humanidad). México, Ed. Planeta, 2007. p 114. Resulta seria la reflexión que hace James Lovelock respecto a que somos demasiados para vivir como vivimos, pero cabe preguntarle al autor: "¿quiénes somos 'nosotros'?". Muy probablemente se refiere a las familias de clase media norteamericanas, cuya emisión de contaminantes es mucho mayor a la de una familia de clase media mexicana. N. del A. 
Todo esto hace pensar que los índices de producción de energéticos que se mantienen en un constante ascenso son igualmente superados de la misma manera debido a un consumo que todavía parece indiscriminado y cada vez más costoso. Si la tecnología no resulta ser la adecuada a los tiempos actuales debido a su indiscriminado consumo de recursos del planeta, entonces ¿cómo tendremos que cambiar nuestros hábitos de consumo para aprovechar óptimamente los recursos?

\section{Entropía}

Antes de seguir en la búsqueda de una respuesta a la búsqueda de una "vivienda energéticamente más eficiente" y de una "vivienda económicamente productiva", es necesario encontrar una explicación bien fundamentada que ligue la vivienda con el desarrollo sustentable, por lo que me veo obligado a explicar el fenómeno de la entropía en la construcción y generación de arquitectura como un problema a estudiar y entender para encontrar así una respuesta adecuada.

El enunciado general de la segunda ley de la termodinámica establece: "La entropía total de cualquier sistema, más la de su ambiente, aumentan como resultado de cualquier proceso natural" ${ }^{20}$ o también de la siguiente manera: "Los procesos naturales tienden a pasar a un sistema de mayor desorden". ${ }^{21}$

En los procesos de transformación de energía como es una combustión en el motor de un automóvil o en la de la energía eléctrica que se transforma para encender la computadora en la que estoy trabajando en estos momentos, una porción de la misma se degrada y la otra porción de la energía se convierte en energía de desecho que está tan desorganizada que no puede utilizarse. La luz del monitor y el calor despedido por el microprocesador no se pueden volver a utilizar, están tan desordenadas y fragmentadas estas formas de energía que "no las podemos pepenar".

Con "no las podemos pepenar" me refiero a que esas energías está tan fragmentadas y desordenadas que no es redituable el captarlas si habláramos en términos económicos, así que "podemos decir que un arreglo más ordenado es aquél que necesita más información para clasificarlo o especificarlo" ${ }^{22}$ por decirlo en términos físicos. Por eso es un problema cuando se transforma la energía eléctrica en calor, movimiento, luz y sonido, porque requiere mucha energía el volver a ordenarla, "saliendo más caro el caldo que las albóndigas." Es más, queda algo que no se puede recuperar, por lo que la segunda ley de la termodinámica establece la degradación de la energía en la que "en cualquier proceso natural, algo de la energía se vuelve inútil para efectuar trabajo útil". ${ }^{23}$

20 GIANCOLI, Douglas. Física (principios con aplicaciones). 3a edición, México, Ed. Prentice Hall, 1994. p 448.

${ }^{21}$ Ibid. p 449.

22 Ibid. p 449: "Cuando tenemos un cuerpo caliente y uno frío, tenemos dos clases de moléculas y dos entidades de información. Cuando los dos cuerpos alcanzan la misma temperatura, sólo hay una clase y una entidad de información. Cuando se mezclan sal y pimienta, sólo hay una clase, uniforme; cuando están en capas, hay dos clases. En este sentido, la información se relaciona con el orden, o sea, con la entropía baja. Es el cimiento sobre el que se levanta la teoría de la información, campo moderno de la ciencia".

23 Ibid. p 450. 


\section{Arquitectura y entropía}

El uso de energía en la arquitectura no es más que la transformación de la energía para generar algo útil para nosotros, esto es tanto en la construcción como en la gestión y destrucción de un edificio. En el caso de los materiales, la naturaleza queda despojada de yacimientos de cantera por poner un ejemplo, o sencillamente el proceso de cocción de los tabiques genera expulsión de CO2 a la atmósfera. Con el uso de la energía aumentamos los niveles de entropía y eso es inevitable en el Universo. Es por eso que aumentan los niveles de $\mathrm{CO} 2$ en la atmósfera, puesto que es un desecho que se está acumulando, y que no sabemos todavía cómo aprovecharlo en la generación de energía o materiales.

Habiendo analizado el fenómeno del arte y sus manifestaciones a través del tiempo, he visto lo suficiente como para darme cuenta que la producción del arte es una de las actividades más entrópicas realizadas por el ser humano. El arte como una producción entrópica encuentra su cumbre en la mayor de sus disciplinas: la arquitectura. Pero en primer lugar es necesario notar la gran diferencia existente entre la arquitectura de estilo y la arquitectura vernácula.

\section{Arquitectura de estilo}

La arquitectura de estilo es la que está inscrita en el campo de la arquitectura como arte, puede ser el caso de los palacios de gobierno, las catedrales, los palacios y espacios públicos como las plazas y los mercados. Es de notar que la arquitectura de estilo a través de los siglos ha tenido la responsabilidad de mostrar un discurso de legitimación del dominio de una clase sobre otra.

En la construcción del $\mathrm{CMI}^{24}$ es necesaria la apropiación de los signos por parte de los flujos del capital (aunque es necesario comentar que eso sucede también con los anteriores modos de producción) ${ }^{25}$ por lo que el CMI reposa sobre varios instrumentos de capitalización del poder subjetivo, el poder subjetivo es apropiado entonces por un discurso a base de $\operatorname{símbolos}^{26}$ que se encuentran presentes en la arquitectura, pero no están solamente presentes, sino que son utilizados en la misma para hacer una propaganda que intenta legitimar la apropiación del plusvalor de las clases oprimidas.

Entonces la arquitectura de estilo ha sido la poseedora tradicional de los símbolos del grupo en el poder, aunque también ha funcionado esta apropiación con otras disciplinas artísticas sobretodo dentro del campo de las artes gráficas. La arquitectura

24 Félix Guattari le llama así al "Capitalismo Mundial Integrado". Vid. GUATTARI, Félix. Las tres ecologías. España, Ed. Pretextos, 2000.

25 N. del A. El arte no solamente se apropia del plusvalor, sino que es construido para justificar la apropiación del plusvalor en un tiempo determinado.

26 Félix Guattari le Ilama "Semiótica de subjetivación". 
de estilo es la actividad que más se apropia de recursos, tanto en el caso de los materiales, como la energía y el plusvalor de las clases oprimidas.

\section{Arquitectura vernácula}

En la construcción de muchos edificios se ha tenido la costumbre de tomar una medida bastante radical: aislarlo totalmente del medio que le rodea para abrir paso a la creación de un microclima independiente del exterior y esto se logra con el uso indiscriminado de aire acondicionado con un abuso en la utilización de energía, pero "los constructores primitivos y los de las culturas actuales con pocos recursos técnicos no podían ni pueden tomar esta actitud, por lo que sus edificios mantienen una estrecha relación con el clima que los rodea"27.

Por lo que esta idea nos explica que las distintas culturas han generado a través de los siglos una arquitectura que saca el mayor provecho de los elementos naturales.

Pero actualmente existen migraciones constantes y mutaciones sistemáticas en los modos de vida de las personas que les hacen renunciar a esta herencia arquitectónica vernácula que ha sido consecuencia de un largo proceso selectivo a través de los siglos en muchas culturas.

En las periferias de la Ciudad de México existe una constante construcción de asentamientos humanos en la que personas llegan a la ciudad en la búsqueda de mejores condiciones de vida y construyen no como sus padres o abuelos lo hicieron en la región de donde son originarios, sino que ante el desorden (hablando entrópicamente) generado en la ciudad, construyen con materiales y recursos que tienen a la mano sin una depuración racional previa. Es por eso que la arquitectura vernácula actual en su desaparición tiende a abrir paso a la autoconstrucción, pero la autoconstrucción necesitará de siglos para depurarse racionalmente.

\section{El nuevo camino de la arquitectura}

¿Cómo es posible que el ser humano se empeñe en la producción de arquitectura de estilo cuando las funciones del arte parecen ser nulas? Hemos visto que la arquitectura de estilo puede transformarse en una propaganda que intente legitimar mediante símbolos la apropiación del plusvalor de las clases oprimidas. Pero es necesario tomar en cuenta que la arquitectura es el testigo de nuestro paso y evolución en este mundo, ya que el arte no se puede reducir de manera tan simplista a la transmisión de una propaganda determinada. Mediante el análisis y el sentido común es responsabilidad nuestra encontrar el discurso que aparece entrelíneas.

Todos los recursos utilizados en la construcción generan un desorden en el ecosistema. Tal vez sea bueno preguntarnos si este desorden es parte de un orden superior en el Universo, pero esta pregunta no resuelve el problema del indiscriminado uso que hacemos de nuestros recursos como para seguir subsistiendo como especie.

27 SERRA Florensa, Rafael; Coch Roura, Helena. Arquitectura y energía natural. México, Ed. Alfaomega, 2005. p 199. 
Si pensáramos que un desorden incapaz de ser ordenado (como parece que sucede) se encuentra dentro de un orden superior establecido en el Universo entonces al Universo le es indiferente la extinción de la raza humana, porque con el ser humano o sin éste el Universo seguirá funcionando. ${ }^{28}$

Entonces si no podemos evitar la entropía, ¿qué podemos hacer? Yo creo que el reto actual de la arquitectura es reducir considerablemente la entropía en la misma, lo que quiere decir que al conseguir energía hay que pensar cómo se va a gastar para utilizarla lo más posible, o enunciándolo a manera de mandamiento: "Conseguirás energía pensando en gastarla lo más sabiamente posible para que te dure más".

Pero al reducir la entropía en los flujos de materiales y energía de la arquitectura debo hacer mención de que esta reducción entrópica que debe ser constante y sistemática debe inscribirse dentro de acciones mundiales y totalizadoras.

El origen de la ciudad se remonta a la necesidad del ser humano de intensificar sus flujos de información, para lo cual tiene que servirse de los ecosistemas que le rodean, tanto naturales como humanos. Es entonces que la ciudad no puede ser nunca sustentable; por extensión la arquitectura, ya que su punto de partida es totalmente lo contrario, del mismo modo el ser humano no es una criatura sustentable por el punto de partida en su evolución. El ser humano nació siempre ávido de superar su condición a expensas de lo otro y eso otro se llama naturaleza o seres humanos.

¿Cuál es el papel de la arquitectura? No solamente intentar reducir considerablemente la entropía en la misma, sino que debe insertarse en un sistema integrador de la raza humana en el que como especie autorregulemos nuestro crecimiento ${ }^{29}$ puesto que de no hacerlo la extinción de la raza humana le sería indiferente al Universo cuando hablamos de que sucesivamente en las eras geológicas han existido especies dominantes como los trilobites que se extinguieron, o como los dinosaurios que se extinguieron; y actualmente los seres humanos somos la especie dominante... si no fuéramos la especie dominante en este planeta no tendríamos ese nivel de problemas al enfrentar la escasez de recursos.

\section{Tendencias actuales de la "arquitectura ecológica"}

Si estamos hablando de la necesidad de reconocimiento de hábitos de consumo y formas de vida que tengan una menor huella ecológica ¿tendremos que retroceder en tecnología ? $^{30}$ Dominique Gauzin-Müller, arquitecta y periodista menciona que "...los

28 N. del A. El Dr. Xavier Vargas Beal (ITESO), me explicó esto de manera muy sencilla: "Cuando el subsistema amenaza con destruir al sistema, el sistema destruirá al subsistema, nunca al revés".

29 N. del A. Con "autorregular nuestro crecimiento" me refiero, entre muchos otros aspectos, a que en primer lugar debemos ser menos habitantes en este planeta, en segundo lugar debemos distanciarnos más y en tercer lugar debemos cambiar de modos de vida, pero el cambio de modos de vida no se da de la noche a la mañana, los modos de vida se construyen inscribiéndose a una cosmogonía, lo que es reconociendo el lugar de cada uno de nosotros en la inmensidad del Universo. Pregunto al lector: ¿Se ha puesto a pensar qué lugar tiene en el Universo? Es más... ¿ha hecho algo por conservar ese lugar en el Universo? No me refiero a qué lugar tiene usted en la sociedad, en la familia, en la ciudad o el campo, por poner un ejemplo, me refiero a la conexión cosmogónica que usted tiene con el Todo.

30 Para averiguar un poco más acerca de la socialización de la ciencia y la tecnología, es necesario ver el apartado: "La socialización de la ciencia y la tecnología" de este estudio. 
partidarios del low tech y del high tech se han visto a menudo enfrentados" ${ }^{31}$ porque ambas tendencias proponen dos formas distintas de enfrentar el problema del gasto energético en la vivienda, siendo básicamente las siguientes:

1. High tech: Generalmente se identifica con las características de la arquitectura de estilo revisadas anteriormente, cuyos máximos representantes se encuentran en arquitectos como Norman Foster, Renzo Piano, Richard Rogers y Thomas Herzog, entre otros. El high tech se caracteriza "por los edificios de oficinas y los grandes equipamientos espectaculares de acero y vidrio de los arquitectos estrella internacionales"32 quienes formaron "READ", una asociación destinada a profundizar en el uso de las energías renovables en la construcción. Como comentario, la entropía generada por utilizar altas tecnologías generalmente llevan a contradicciones del concepto de Desarrollo Sustentable; como el caso de usar materiales que en su producción y transporte generan más impactos negativos en el ambiente que en su uso.

2. Low Tech: Se identifica mucho con la arquitectura vernácula, actuando sobre todo en programas residenciales y pequeños equipamientos educativos y culturales. Esta tendencia surge de los movimientos contestatarios de 1968 en Francia, pero en México halló una buena acogida en el Autogobierno de la Facultad de Arquitectura de la UNAM de los años 70's. Consiste sobre todo en la atención a los grupos que no ostentan el poder y que al tener escasez de recursos requieren una inventiva diferente en su ejecución. Resulta interesante el trabajo de arquitectos como Paolo Soleri y Heladio Dieste.

\section{Una vivienda económicamente productiva}

Además de preguntarnos: "¿Para qué quiere nuestro país una vivienda energéticamente más eficiente se añade la de: ¿Qué ventajas encuentra nuestro país en la promoción de una vivienda económicamente productiva bajo el esquema de la agricultura urbana?

La repercusión de los gastos energéticos de la vivienda en la economía familiar necesita soluciones y parece haberlas: "Los estudios clásicos sobre el universo familiar de la favela enfatizan la centralidad de la vivienda en sus estrategias de supervivencia" ${ }^{33}$. La vivienda en las favelas es el locus de acumulación de bienes duraderos. Es de notar que se pueden encontrar soluciones a los embates de la economía familiar tomando a la vivienda como centro de inversión patrimonial familiar, pero desgraciadamente la plasticidad espacial de las favelas las colocan en el mercado inmobiliario informal. ¿Existen elementos aplicables a la vivienda formal? ¿Conviene aplicarlos?

Paralelamente a esto, es importante señalar lo siguiente:

GAUZIN-MÜLLER, Dominique. Arquitectura ecológica (29 ejemplos europeos). España, Ed. GG,

32 Ibid. $p 16$.

33 ABRAMO, Pedro. La teoría económica de la favela: cuatro notas sobre la localización residencial de los pobres y el mercado inmobiliario informal. Revista Ciudad y Territorios: Estudios territoriales, vol. XXXV, n. 136-137, verano-otoño 2003, Ministerio de Fomento, España. p 2. 
El movimiento ecológico nació mucho antes de que el deterioro del medio y de la calidad de vida plantearan una cuestión de supervivencia a la humanidad. Nació originalmente de una protesta espontánea contra la destrucción de la cultura de lo cotidiano por los aparatos de poder económico y administrativo. Y por 'cultura de lo cotidiano' entiendo el conjunto de saberes intuitivos, de savoir-faire vernáculos (en el sentido que Ivan Illich da a este término), hábitos, normas y modos de conducta, gracias a los cuales los individuos pueden interpretar, comprender y asumir su inserción en el mundo que los contiene. ${ }^{34}$

Esto quiere decir que lo que está en juego es nuestra vida humana, siendo necesaria su reinterpretación desde un punto de vista más profundo, incluso desde la inserción del ser humano en el Universo, por lo que la vivienda es un buen punto de partida ya que es el lugar de los primeros contactos humanos y su construcción. Es el lugar originario después del útero materno en donde se crean lazos de amor, pero también de odio que se trasladan a la sociedad desde la familia. Es en donde el ser humano aprende a reconocerse en el otro y a establecer luchas de poder y alianzas.

En la vivienda es necesario encontrar un modelo de la misma cuyos procesos puedan desligarse en gran medida del proceso de acumulación del capital para generar una alternativa de acumulación de bienes dentro del modo de producción capitalista y atender a la necesidad del ser humano por la defensa de la vida. Esta acumulación de bienes se refiere sobre todo a los que suelen ser más valiosos que el dinero y que están actualmente muy subvalorados.

La "defensa del mundo vital"35 es la tarea originaria de la defensa de la naturaleza y de la centralidad de la vivienda en la implementación de un modelo como el que se desarrolla en este estudio; la defensa de la vida humana y su calidad de vida está de por medio; incluso André Gorz explica lo siguiente:

Las megatecnologías a favor de las cuales las industrias privadas y/o las administraciones públicas desposeían a los ciudadanos de su medio de vida] alienaba a los habitantes lo poco que les quedaba del medio "natural", los agredía por sus incomodidades $y$, fundamentalmente, confiscaba el dominio público en provecho de los aparatos técnicos que simbolizaban la violación que el capital y el Estado hacían del derecho de los individuos a determinar por ellos mismos su manera de vivir juntos, de producir y de consumir. ${ }^{36}$

El implantar el mayor número posible de ecotecnias a un hogar junto con un medio parcial de subsistencia ${ }^{37}$ en el modelo que se desarrolla en este estudio puede contribuir en la reducción de emisiones contaminantes en la producción y

34 GORZ, André. Ecología política. Expertocracia y autolimitación. Nueva Sociedad no. 134 Noviembre-Diciembre 1994, pp 32-41 ver página: www.nuso.org/upload/articulos/2373_1.pdf (ingresada el 11 de marzo de 2009), p 4. Nótese cómo el autor hace mención a una necesidad del ser humano por "...comprender y asumir su inserción en el mundo que los contiene", porque a eso se refiere la cosmogonía y a lo que refiero en la nota 29 al pie de página.

35 Ibid. p 4.

36 Ibid. p 5.

37 Como es la agricultura urbana. 
aprovechamiento de energía y alimentos, además de que también contribuye socialmente a la conformación y/o afirmación de procesos familiares e individuales de autogestión, autorregulación y autosupervisión, recuperando el valor de los lazos familiares y sociales por encima de los lazos originados por los valores monetarios.

Entonces, la implementación de un modelo de vivienda en el que se construya la independencia energética y alimentaria familar deberá tener las siguientes ventajas:

- Reducción de emisión de contaminantes.

- Aprovechamiento de energía y alimentos.

- Ahorro de recursos económicos.

- Afirmación de los procesos de autogestión, autorregulación y autosuper-visión dentro de los lazos familiares.

- La vivienda entonces se convierte en vivienda y no solamente en dormitorio: es de notar que para la implantación de este modelo se necesita una parte del tiempo de cada uno de los integrantes. ${ }^{38}$ Según André Gorz:

La política ecosocial consiste principalmente en garantizar un ingreso suficiente, independiente de la jornada de trabajo (la que no puede sino decrecer) y eventualmente del trabajo mismo: para distribuir el trabajo socialmente necesario de manera que todo el mundo pueda trabajar y trabajar a la vez mejor... ${ }^{39}$

Las propuestas del modelo presentado en este estudio van dirigidas a revertir procesos como el siguiente:

El trabajador individual no es "más que un accesorio vivo de esta maquinaria", su capacidad de trabajo individual desaparece por ser infinitamente pequeña, del mismo modo que desaparece en el producto toda relación con la necesidad inmediata del productor y por consiguiente con el valor de uso inmediato. ${ }^{40}$

Esto quiere decir que el ser humano, dentro de esa maquinaria empieza a olvidar que el dinero es tan solo la cosa de las cosas, la cosa que ayuda a conseguir otras cosas, pero esas cosas se pueden conseguir directamente.

Erich Fromm explica también la importancia de emancipar al ser humano de los procesos que supeditan sus necesidades claramente humanas a las de los flujos del capital:

38 N. del A. La cuestión tiempo podría ser una variable que a grandes rasgos parecería contraproducente, es decir, cada integrante trabaja determinado tiempo para obtener recursos para la familia fuera de la vivienda; lo que pretende este modelo es alternar tiempo de trabajo fuera y dentro de la vivienda. Con trabajo dentro de la vivienda quiero decir que no es una especie de "freelance" el que propongo, ya que el "freelance" es un trabajo para una entidad externa que se apropia del plusvalor. Trabajo dentro de la vivienda es un trabajo en el que pretendo que los integrantes de la familia se apropien del plusvalor que están generando.

39 GORZ, André. Op. cit. p 13.

40 Ibid. p 9-10. 
El fin de Marx era la emancipación espiritual del hombre, su liberación de las cadenas del determinismo económico, su restitución a su totalidad humana, el encuentro de una unidad y armonía con sus semejantes y con la naturaleza. ${ }^{41}$

El modelo que se presenta en este estudio está encaminado a ese fin, empezando por casa dentro de lo familiarmente posible.

\section{Retos del modelo de vivienda}

Ha habido señales de alarma respecto a la ineficacia del actual modelo económico para presentar una solución a los verdaderos problemas humanos, "en los últimos meses se han registrado levantamientos provocados por la escasez de alimentos en 22 países" ${ }^{42}$ y mantiene bajo presión a otros tantos y esto se debe en gran parte a una distorsión artificial que se hace del mercado mundial agrícola. Mientras las naciones desarrolladas pueden otorgar subsidios a sus productores, las que están en vías de desarrollo sólo pueden competir en el libre mercado de manera desigual (como es el caso del TLCAN que obliga a México a competir de manera muy desventajosa), por lo que las segundas importan productos agrícolas de las primeras.

Añadimos también la depreciación del nivel adquisitivo del salario mínimo en México (ha descendido en el 2006 hasta un $69.25 \%$ con respecto a 1970 , es decir, a 1/3). ${ }^{43}$ Esto nos lleva a pensar que la implementación del "estado nacional de competencia" 44 presenta muchos problemas, ya que los países en vías de desarrollo perdieron su estatus protector hacia la población que habita en sus territorios ante la presión de empresas que requieren mano de obra barata. Familias que se encuentran en un nivel socioeconómico medio también estarán obligadas a empobrecerse.

Desempleo de laPEA

Primer trimestre del año (enero-febreno-marzo)

\begin{tabular}{|c|c|c|c|}
\hline & 2007 & 2008 & 2009 \\
\hline Según INEGI & $3.99 \%$ & $3.91 \%$ & $5.02 \%$ \\
\hline
\end{tabular}

\section{Tabla 02}

Desempleo de la PEA en los primeros trimestres del trienio 2007-2009

Fuente: INEGI, ver página: www.inegi.org.mx/lib/buscador/busqueda.aspx?s=inegi (ingresada el 23 de abril de 2009).

\footnotetext{
41 FROMM, Erich. Marx y su concepto del hombre. México, Ed. FCE, 2005, p 21.

42 FOROOHAR, Rana. "La peor crisis de todas" en: Newsweek en español. Vol. 12, no. 20. 19 de mayo de 2008. pp. 16-21.

43 Datos obtenidos de www.mexicomaxico.org/Voto/SalMinInf.htm (ingresada el 13 de septiembre de 2008) y concuerdan con los de la SHCP (Secretaría de Hacienda y Crédito Público) de México.

44 HIRSCH, Joachim. El Estado Nacional de Competencia: Estado, democracia y política en el capitalismo global. México, UAM, 2001.
} 
El desempleo de la $\mathrm{PEA}^{45}$ ha crecido constantemente y las repercusiones de la recesión económica actual obligan a desarrollar estrategias de supervivencia familiar que se desliguen lo más posible de los aspectos macroeconómicos. La tabla 2 parece muy optimistsa en relación al terrible deterioro que ha sufrido nuestro país.

El desarrollo de estrategias de supervivencia familiares más ligadas a nuestra realidad, fuera de un abstraccionismo reduccionista macroeconómico permitiría un acceso a una mejor calidad de vida de casi cualquier familia y les permitiría una mayor libertad de movimiento económico. ${ }^{46}$

Si en una vivienda se pueden producir artículos agrícolas, con un excedente se puede desarrollar una economía de intercambio que tal vez podría coexistir con una economía monetaria. Tal vez a largo plazo esto permita generar una opción de supervivencia para las familias al alternar entre estos tipos de economía (monetaria y de intercambio) según la temporada de mayor o menor ingreso económico y según la capacidad de crecimiento de la macroeconomía de los países en vías de desarrollo.

Este tipo de modelos deberán incluir las siguientes características bajo la propuesta de un modelo de acumulación de bienes familiares (no únicamente económicos) con la puesta en práctica de dos tipos de estrategias:

- Eficiencia energética en la vivienda

- Una vivienda económicamente productiva

Pero siempre dirigidas al desarrollo de la vivienda en un papel central que contribuya en las estrategias de supervivencia familiar y consolidación patrimonial.

También se deberán dirigir a generar una alternativa microeconómica centralizada en la vivienda como objeto al cual se dirigen las inversiones patrimoniales en las estrategias de supervivencia familiar. El realizar modelos que abarquen características similares es de vital importancia para entender la necesidad de regionalizar la planificación, es decir, adaptarla a cada singularidad social, ecológica y económica. Pablo Gutman llama a establecer un contrapeso creativo, es decir, algo que se presente como opción a la tendencia homogeneizadora de la creación de necesidades artificiales en los bienes de consumo.

\section{Socialización de la ciencia y la tecnología}

Mucho se ha dicho acerca de la profundidad de la problemática ambiental, en la que aparece no sólo la crisis ambiental, sino una crisis profunda del pensamiento y del entendimiento, La crisis surge de cómo el pensamiento occidental ha comprendido el ser hasta ahora.

45 PEA: Población Económicamente Activa.

46 Aunque hay que aclarar que los modelos serán muy diferentes de acuerdo a las características de cada familia. N. del A. Las familias que migran del campo a la ciudad suelen reproducir este modelo de vivienda, aunque pertenecen a la economía informal. 
Desde el punto de vista marxista, la ciencia y la tecnología han sido instrumentos de los flujos del capital y más intensamente en nuestros días, en el CMI. ${ }^{47}$ Basta echar una mirada en cualquier aparador y encontramos una gran cantidad de productos que intentan vendérsenos y que pertenecen a este campo, como son los teléfonos celulares, las cámaras, los televisores, reproductores de música o equipos de cómputo. iQué curioso es el ser humano que teniendo un teléfono móvil, decide comprar otro no por su capacidad de comunicación sino por la moda!

La ciencia y la tecnología han desarrollado productos que funcionan solamente por unos años antes de ser desechados; el objetivo del desarrollo de la ciencia y la tecnología parece acercarse tanto a las necesidades de los flujos de capital en el CMI que han olvidado el cometido que tienen de resolver los problemas de la humanidad y vencer las desigualdades humanas:

(...) resulta evidente que esta nueva etapa de la humanidad, a pesar de sus innegables avances, no está superando los problemas de la anterior, entre ellos la profunda inequidad social, el predominio de autoritarismos políticos, la erosión de una ética cimentada en el compromiso y la solidaridad humanas, las desigualdades de género y el acelerado deterioro ecológico. ${ }^{48}$

Es evidente también que habiendo tantos problemas por resolver la ciencia peleé cada vez más por encontrar escaños que justifiquen su desarrollo, que justifiquen su utilidad y que no la hagan ver como inútil. Existe normalmente en los campos científicos aseveraciones como: "sí, es muy buena idea, resolvería muchos problemas, pero nadie invertiría en ello porque lo redituable sólo se encuentra en el campo social, no existe una ganancia económica", por poner un ejemplo.

La socialización de la ciencia ha sido un asunto pendiente que no se ha resuelto del todo, salvo contadas excepciones. Es por eso que rescato la frase que cité en la introducción de este estudio y que es la siguiente: "¿Está capacitada la ciencia ante la tarea que enfrentamos -equipar a las sociedades humanas para manejar el medio ambiente de manera sustentable?"49

En muchos casos, la investigación se lleva a cabo en un lugar determinado para traer "beneficios" a una sociedad determinada, pero resulta que el investigador no se atreve a preguntar a los supuestos beneficiarios de su investigación acerca del medio en el que se desenvuelven, debiendo utilizar herramientas como el Diseño Participativo. Suele existir una clara imposición y es por eso que la ciencia y la tecnología toman caminos que se dirigen a contribuir a los flujos del capital del CMI y no a resolver los problemas de la humanidad.

Siempre ha existido la injusticia social, sólo que cambia de forma y es la ciencia la encargada de identificarla y no sólo eso, sino darle solución. El problema mayor que se

47 N. del A. Voy a tomar el concepto de Félix Guattari en el que CMI es la abreviatura de "Capitalismo Mundial Integrado". Ver nota 18. N.

48 REYES Ruiz, Javier. La participación social en la investigación de problemas ambientales.

49 REDCLIFT, Michael. A nuestra propia imagen: el medio ambiente y la sociedad como discurso global En: L. Arizpe (ed.), Las dimensiones culturales del cambio global: una perspectiva antropológica. Cuernavaca, UNAM, Centro de Investigaciones Multidisciplinarias. 
observa en estas nuevas formas de desequilibrio humano, es que tanto la injusticia social como la ambiental y la económica nos pueden llevar a la extinción de la especie humana.

\section{Conclusiones}

Existe un error constante en la concepción de la vivienda como si fuera exclusivamente una mercancía, cuando se debería contemplar como el hogar en el que se originan los lazos familiares con un gran potencial de mejoramiento en la calidad de vida de los seres humanos.

Es necesario destacar que países como México no presentan emisiones de $\mathrm{CO} 2$ tan elevadas como para llevar la pauta en la búsqueda de una eficiencia energética en la vivienda, porque esa pauta la deben llevar los países desarrollados y los que más contaminan, a tal punto de que de existir los "puntos de carbono" los países desarrollados deberían pagarle una indemnización a los países en vías de desarrollo.

Las actuales tendencias de muchos estados en vías de desarrollo se centran en exponer la seguridad familiar al libre mercado, este problema clama por una solución adecuada que encuentra atractivo el desarrollo de una vivienda energéticamente eficiente y económicamente productiva.

La arquitectura es la disciplina que se encarga de analizar la construcción de la vivienda, por lo que es conveniente encaminarla dentro de estos procesos económicos, políticos y ambientales para no soslayar la misión que tiene en la construcción de los hogares, diseñando la gestión entrópica en las mismas dentro de sus distintas vertientes como el High-tech y el Low-tech entre otras.

El contemplar la socialización de la ciencia mediante herramientas como el Diseño Participativo podría generar un círculo virtuoso de satisfacción de la familia con su vivienda, en la construcción de la independencia energética y alimentaria familiar para la construcción, a su vez, del patrimonio familiar un poco fuera de las incertidumbres presentadas por los flujos del capital y la especulación económica.

\section{Bibliografía}

Abramo, Pedro. La teoría económica de la favela: cuatro notas sobre la localización residencial de los pobres y el mercado inmobiliario informal. Revista Ciudad y Territorios: Estudios territoriales, vol. XXXV, n. 136-137, verano-otoño 2003, Ministerio de Fomento, España. Pp. 273-294. ISSN: 1133-4762

Bartra, Roger. Marxismo y sociedades antiguas: El modo de produccion asiatico y el mexico prehispanico. Ed. Grijalbo 1975.

Castro Soto, Gustavo. Radiografía de la Electricidad en México. Ver página: www.ecoportal.net/content/view/full/67368 (ingresada el 20 de septiembre de 2009).

Clive, Pointing. Historia verde del mundo. México, Ed. Paidós, 1992. ISBN: 8475098401 ISBN-13: 9788475098401. 
Compendio de salarios mínimos. Ver página: www.mexicomaxico.org/Voto /SalMinInf.htm (ingresada el 13 de septiembre de 2008).

Edwards, Brian. Guía básica de la sostenibilidad. España, Ed. Gustavo Gili, SA, 2005. ISBN: 84-252-1951-5.

Fernández, Roberto. Ciudad, arquitectura y la problemática ambiental. En LEFF, Enrique Los problemas del conocimiento y la perspectiva ambiental del desarrollo. México, Ed. S. XXI, 2000. ISBN: 968-23-2277-4.

FOROOHAR, Rana. "La peor crisis de todas" en: Newsweek en español. Vol. 12, no. 20. 19 de mayo de 2008. pp. 16-21, ISSN: 1091-3416.

Fromm, Erich. Marx y su concepto del Hombre. México. Ed. FCE, 2005, 272 pags., ISBN: 968-16-0188-2.

GARCÍA Acosta, Virginia. El estudio histórico de los desastres. En VIRGINIA GARCÍA Acosta, coord. Estudios históricos sobre desastres naturales en México: balance y perspectivas [et al.]. México, CIESAS, 1992, ISBN: $9789684962224,9684962223$.

Gauzin-Müller, Dominique. Arquitectura ecológica (29 ejemplos europeos). España, Ed. GG, 2006, ISBN-13: 978-84-252-1918-4, ISBN-10: 84-252-1918-3.

Giancoli, Douglas. Física (principios con aplicaciones). 3a edición, México, Ed. Prentice Hall, 1994, ISBN: 968-880-369-0.

Gorz, André. Ecología política. Expertocracia y autolimitación. Nueva Sociedad no. 134 Noviembre-Diciembre 1994, pp 32-41 ver página: www.nuso.org/ upload/articulos/2373_1.pdf (ingresada el 11 de marzo de 2009). ISSN: 0251-3552

Guattari, Félix. Las tres ecologías. España, Ed. Pretextos, 2000, ISBN: 84-87101-29-1.

Hirsch, Joachim. El Estado Nacional de Competencia: Estado, democracia y política en el capitalismo global. México, Universidad Autónoma Metropolitana, 2001. ISBN: 970654-903-X.

Lovelock, James. La venganza de la Tierra (la teoría de Gaia y el futuro de la humanidad). México, Ed. Planeta, 2007. ISBN-13: 978-970-37-0245-9. ISBN-10: 97037-0245-7.

Martínez Alier, Joan. El ecologismo de los pobres. España, Ed. ICARIA-FLACSO. ISBN: 8474267439 ISBN-13: 9788474267433.

MILLER, Peter. "Ahorro de energía, se empieza en casa" en: National Geographic en español. Vol 24 no. 03. Fecha de publicación: 26 de febrero de 2009. pp. 2-23, ISSN: 1665-7764.

Ministerio de Industria, Energía y Turismo de Islandia. Ver página: www.statice.is (ingresada el 20 de septiembre de 2009). 
National Geographic. Energy for tomorrow (repowering the planet). Collector's edition. 2009. ISSN 1536-6596.

O'Connor, James. ¿Es el capitalismo sostenible? En ALIMONDA, Héctor (comp.) Ecología política, naturaleza, sociedad y utopía. Buenos Aires, CLACSO, abril de 2002 ISBN: 950-9231-74-6. Ver página: http://bibliotecavirtual.clacso. org.ar/ar/libros/ecologia/ecologia.html (ingresada el 19 de febrero de 2010).

Portal Cubano de la Energía. Estadísticas de Energía de Cuba a partir del Anuario de Cuba del 2007. Ver página: www.energia.inf.cu (ingresada el 20 de septiembre de 2009).

Portal de energía de los Emiratos Árabes Unidos. Ver página: www.eia.doe.gov/emeu/cabs/ UAE/Full.html (ingresada el 20 de septiembre de 2009).

Redclift, Michael. A nuestra propia imagen: el medio ambiente y la sociedad como discurso global. En ARIZPE, Lourdes (ed.), Las dimensiones culturales del cambio global: una perspectiva antropológica. Cuernavaca, UNAM, Centro de Investigaciones Multidisciplinarias. ISBN: 9683663826, 9789683663825.

Reyes Ruiz, Javier. La participación social en la investigación de problemas ambientales. En OYAMA, Ken; Castillo, Alicia. Manejo, conservación y restauración de recursos naturales en México. México, Ed. S XXI, 2006. ISBN 968-23-2649-4, 9789682326493.

Serra Florensa, Rafael; Coch Roura, Helena. Arquitectura y energía natural. México, Ed. Alfaomega, 2005. ISBN: 970-15-0820-3.

Toledo, Víctor Manuel. Ecología, sustentabilidad y manejo de recursos naturales: la investigación científica a debate. En OYAMA, Ken; Castillo, Alicia. Manejo, conservación y restauración de recursos naturales en México. México, Ed. S XXI, 2006. ISBN 96823-2649-4, 9789682326493.

World Bank. Ver datos: http://web.worldbank.org/WBSITE/EXTERNAL/ DATASTATISTICS/0, contentMDK:20535285 menuPK: $1192694 \sim$ pa gePK:64133150 pi PK:64133175 theSitePK:239419,00.html (ingresada el 20 de septiem-bre de 2009). Se trata de datos del año de 2005. 